DOI 10.37882/2223-2974.2020.12.03

\title{
РАЗВИТИЕ СОЦИАЛЬНОГО ПРЕДПРИНИМАТЕЛЬСТВА НА ОСНОВЕ ФОРМИРОВАНИЯ СИСТЕМНОЙ МОДЕЛИ СОЦИАЛЬНОГО ПАРТНЁРСТВА ${ }^{1}$
}

\section{DEVELOPMENT OF SOCIAL ENTREPRENEURSHIP ON THE BASIS OF FORMATION OF A SYSTEM MODEL OF SOCIAL PARTNERSHIP}

\section{Androsova \\ Yu. Polozhentseva}

Summary: The modern period of development is characterized by the presence of acute social problems, which require a comprehensive interaction of available resources and opportunities in the face of the state, business and society in the form of social partnership. The article describes an approach to the formation of a system model of social partnership based on the cooperation of authorities, target groups of the population and social entrepreneurship. The study provides digital data on the territorial distribution of social enterprises and their types of activity; examples of successfully functioning social behavioral structures are given. The authors propose a system model of social partnership, the main participant of which is socially oriented business structures. Social partnership will open up new opportunities for socio - economic development: improving the quality of life of the population; assistance to socially vulnerable groups of society; financing socially significant projects.

Keywords: social entrepreneurship; social partnership; region; system model; target population groups.

\author{
Андросова Ирина Владимировна \\ К.э.н., дочент, ФГБОУ ВО «Юго-Западный государственный \\ университет» (2. Курск) \\ irinka-rusik@mail.ru \\ Положенцева Юлия Сергеевна \\ К.э.н., доцент, ФГБОУ ВО «Юго-Западный государственный \\ университет» (2. Курск) \\ polojenceva84@mail.ru
}

Аннотация: Современный период развития характеризуется наличием острых социальных проблем, для решения которых необходимо комплексное взаимодействие имеющихся ресурсов и возможностей в лице государства, бизнеса и общества в форме социального партнёрства. В статье изложен подход к формированию системной модели социального партнерства на основе кооперации органов власти, целевых групп населения и социального предпринимательства. В исследовании приведены цифровые данные по территориальнму распределению социальных предприятий и их видам деятельности; приведены примеры успешно функционирующих бизнес-структур социальной направленности. Авторами предложена системная модель социального партнёрства, основным участником которого выступают социально ориентированные предпринимательские структуры. Социальное партнерство позволит открыть новые возможности социально- экономического развития: повышение качества жизни населения; помощь социально незащищенным группам общества; финансирование социально значимых проектов.

Ключевые слова: социальное предпринимательство; социальное партнерство; регион; системная модель; целевые группы населения.
B условиях трансформации российского общества одно из направлений деятельности государства фокусируется на решении различных проблем социального характера: сокращение безработицы и социальной напряженности; сдерживание процесса дифференциации населения; развитие и совершенствование системы образования и подготовки кадров; поддержка социально уязвимых категорий общества [5, с.211]. Для обеспечения минимизации экономических и социальных последствий данных проблем необходимо формирование модели социального партнерства, основывающейся на постоянном взаимодействии представителей разных стратификационных «срезов» современного общества: государственных властных органов, предпринимательских структур, экономически активного (в т.ч. безработных) и неактивного (включая рантье, иждивенцев и пр.) населения, - и направленной на согласование и защиту интересов всех групп влияния и участников [9, c.118]. Основными принципами, лежащими в основе социального партнерства, являются: кооперация усилий и возможностей участников-партнеров по решению социальных задач; учет интересов каждого из партнеров; выгодные (экономически, социально, политически, психологически и пр.) для всех условия взаимодействия. Значительная роль в построении эффективного партнерства отводится предпринимательству, направлен-

1 Исследование выполнено при поддержке гранта Президента РФ по государственной поддержке ведущих научных школ РФ № НШ-2702.2020.6 «Концептуальные основы новой парадигмы экономического развития в эпоху технологической и социальной трансформации» 
ному решение остро стоящих проблем в обществе. Объект такого вида предпринимательства - это конкретная социальная проблема. Субъект же социального предпринимательства определяется гораздо сложнее. Существуют два подхода к его определению:

это может быть как сам социальный предприниматель, так и все участвующие в проекте стороны, для которых решение самой социальной проблемы является целью всего бизнеса. Данную деятельность могут осуществлять как физические (частные), так и юридические лица [1, с.97]. Принципами социального предпринимательства являются инновационность, самоокупаемость, финансовая устойчивость. Основным фактором, отличающим данный тип предпринимательства от традиционного, является наличие социальных возможностей, используемых предпринимателями. Кроме того, в основе каждого социального предпринимательства лежит какая-либо проблема, дающая возможность для бизнес деятельности. Решение же этих проблем (в области здравоохранения, образования, экономики, искусства и др.) - это альтернативные пространства профессиональной деятельности, использование новых технологий, инноваций. Стоит также отметить, что социальный предприниматель отличается еще и готовностью понести убытки для решения той или иной проблемы. Именно поэтому внутренние ценности, мотивация и даже мировоззрение самого предпринимателя значительно влияют на сам бизнес. Иными словами, социально ориентированный бизнес сочетает в себе и предпринимательский подход, и социальную направленность, то есть, находится на стыке предпринимательства и благотворительности. Важно также понимать, что полученные материальные средства не идут на распределение между собственниками организации, они реинвестируются, что также, в свою очередь, является еще одной отличительной чертой социального предпринимательства [6, с.673].

Для России понятие социального предпринимательства относительно молодо. Впервые оно появилось в академическом мире в конце 1990-х годов благодаря усилиям таких исследователей как Билл Дрейтон и Чарльз Лидбитер. Однако как профессиональную область социальное предпринимательство представил Грегори Диз. Позже оно получило признание и со стороны государства. После этого идею социального предпринимательства поддержал и Майкл Янг, создавший институт изучения обществ, предметом поддержки и исследования которого стали социальные организации. Также большую роль в развитие социального предпринимательства внес такой деятель как Мухаммад Юнус, основавший банк, выдающий кредиты малоимущим гражданам, что получило свое развитие еще в 58 странах мира [7, с.33].

В российской практике в июле 2019 года официально введены в законодательство понятия социального предпринимательства и социального предприятия. После принятия поправок в закон, субъекты малого и среднего бизнеса иметь право претендовать на статус социального предприятия при выполнении ряда условий: принадлежность к конкретным «социальным» сферам деятельности; не менее половины наемного персонала социально уязвимые категории населения; ориентация на достижение общественно полезных целей; способствование решению социальных проблем; производство и обеспечение доступа товаров и услуг на рынок для социально незащищенных слоев населения [10].

В настоящее время в России функционирует более пяти тысяч социальных предприятий и предпринимателей, занимающихся различными видами деятельности (рис.1). Наиболее популярными видами деятельности являются образовательные услуги (19,77\%), далее идут социально ориентированные НКО $(17,14 \%)$, третья позиция принадлежит сфере услуг. Основное предназначение образовательных услуг для социальных категорий населения заключается в проведении курсов для повышения компьютерной и финансовой грамотности среди пенсионеров, осуществления адаптированных образовательных программ для инвалидов и лиц с ограниченными возможностями. Помимо выделенных видов социальный бизнес концентрируется на социальном обслуживании населения, физической культуре и спорте, здравоохранении, культурно-просветительской деятельности и прочее.

Важной характеристикой социального предпринимательства является его территориальное расположение (рис.2).

Данные рисунка 2 показывают распределение социального предпринимательства в разрезе регионов [2, с.114]. Наибольшее количество социальных предприятий и предпринимателей сосредоточено в Центральном Федеральном округе - 30,29\% Северо-западном округе - 19,07\%, Приволжском - 18,43\%. В Северо-Кавказском Федеральном округе функционирует всего лишь 15 социально ориентированных бизнес-структур, т.е. в данном округе социальное предпринимательство развито слабо.

Практика социального предпринимательства Курской области, входящей в состав Центрального федерального округа - лидера по численному количеству бизнес-структур, показывает, что на территории региона функционируют пять организаций. Яркую социальную окраску несут такие организации как ООО «Медико-реабилитационный центр Орто-Доктор им. Алехина Ю.И.», магазин «Зайка - Сдайка», ООО «Компания Макс». Центр оказывает услуги по протезированию, массажу, консультациям психолога женщинам, перенесшим онко- 


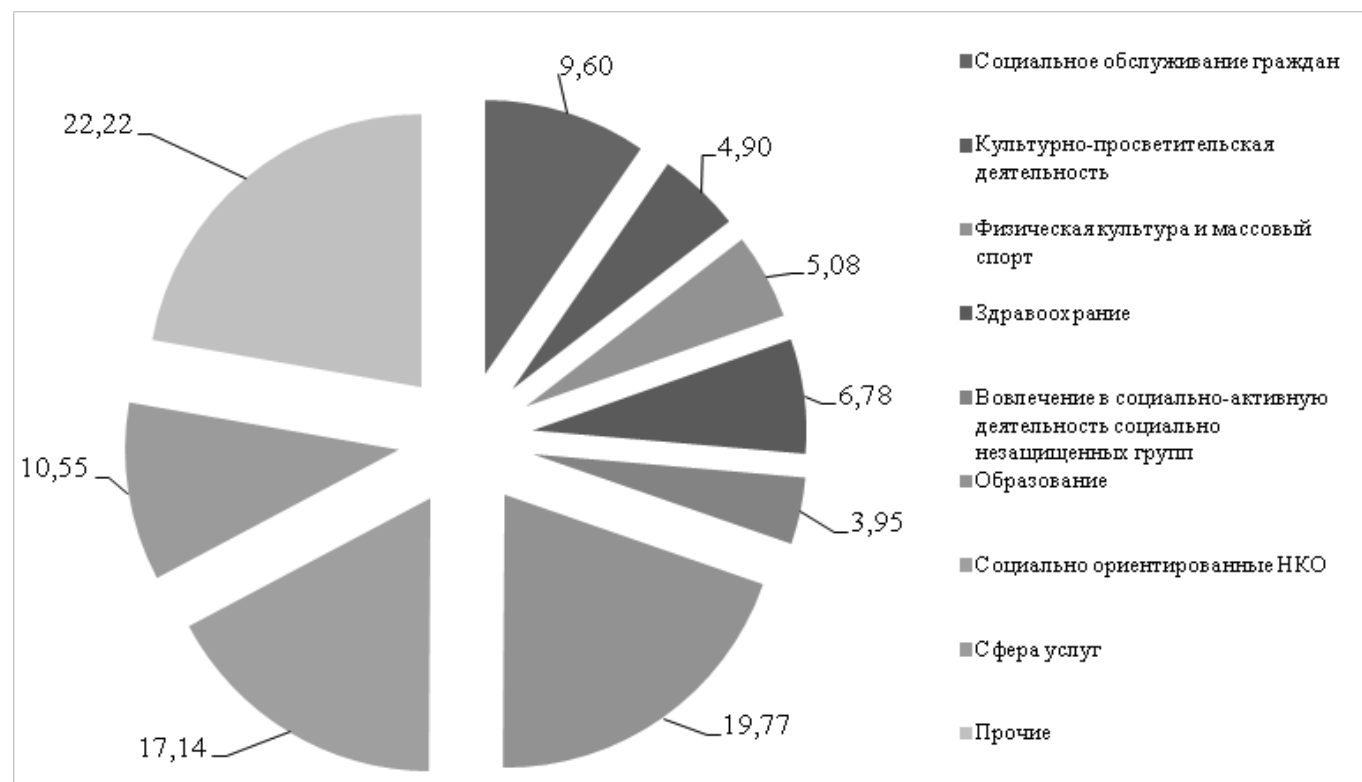

Рис. 1. - Распределение социально ориентированного бизнеса по видам деятельности, \% [4]

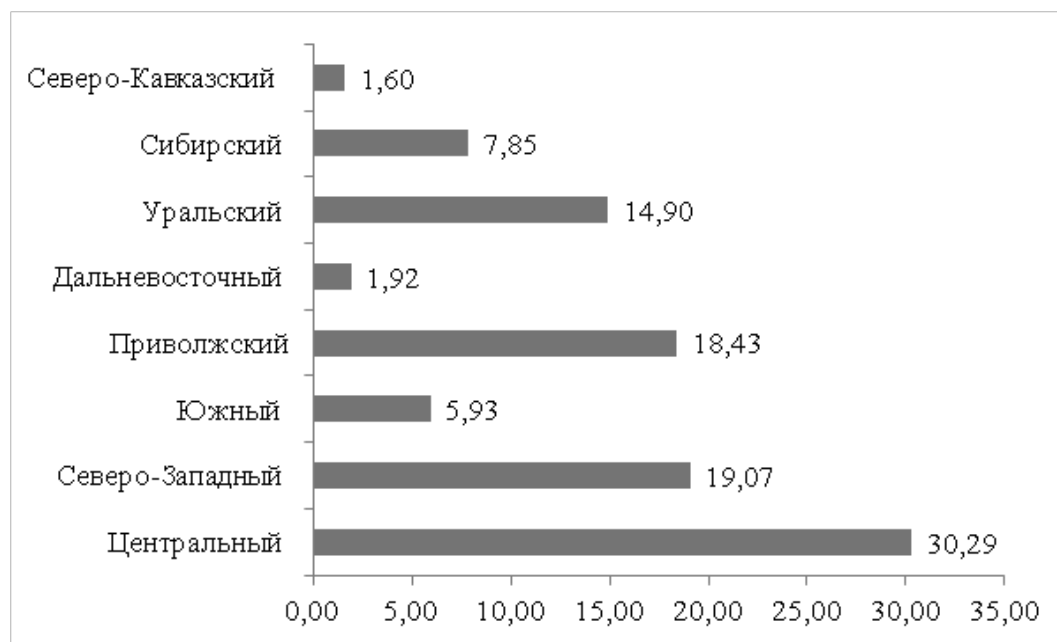

Рис. 2. - Региональное распределение социального предпринимательства, \% [4]

логические заболевания. Еще одним примером является комиссионный магазин «Зайка-Сдайка», направленный на решение социальной проблемы - помощь малоимущим и многодетным семьям по обеспечению их детской одеждой. Компания Макс специализируется на установке и обслуживании детских и спортивных площадок для лиц с ограниченными возможностями. Таким образом, на территории Курского региона есть примеры успешного функционирования социально ориентированных предприятий. Однако в настоящее время существует ряд проблем, препятствующих более эффективному их развитию:

- низкий уровень информированности населения о вопросах, целях, задачах такого вида предпринимательства. Большинство граждан не ознакомлено с понятием социального предпринима- тельства, и, как следствие, не уделяют должного внимания данному явлению;

- проблема финансирования для развития социального предпринимательства. В настоящий момент социальные предприниматели нацелены на привлечение спонсоров, получение государственной поддержки;

- отсутствие некой профессиональной площадки социальных предпринимателей и единомышленников для обмена опытом.

Для решения выделенных проблем необходимо формирование системной региональной модели социального партнёрства (рис.3)*.

Разработанная системная модель регионального со- 


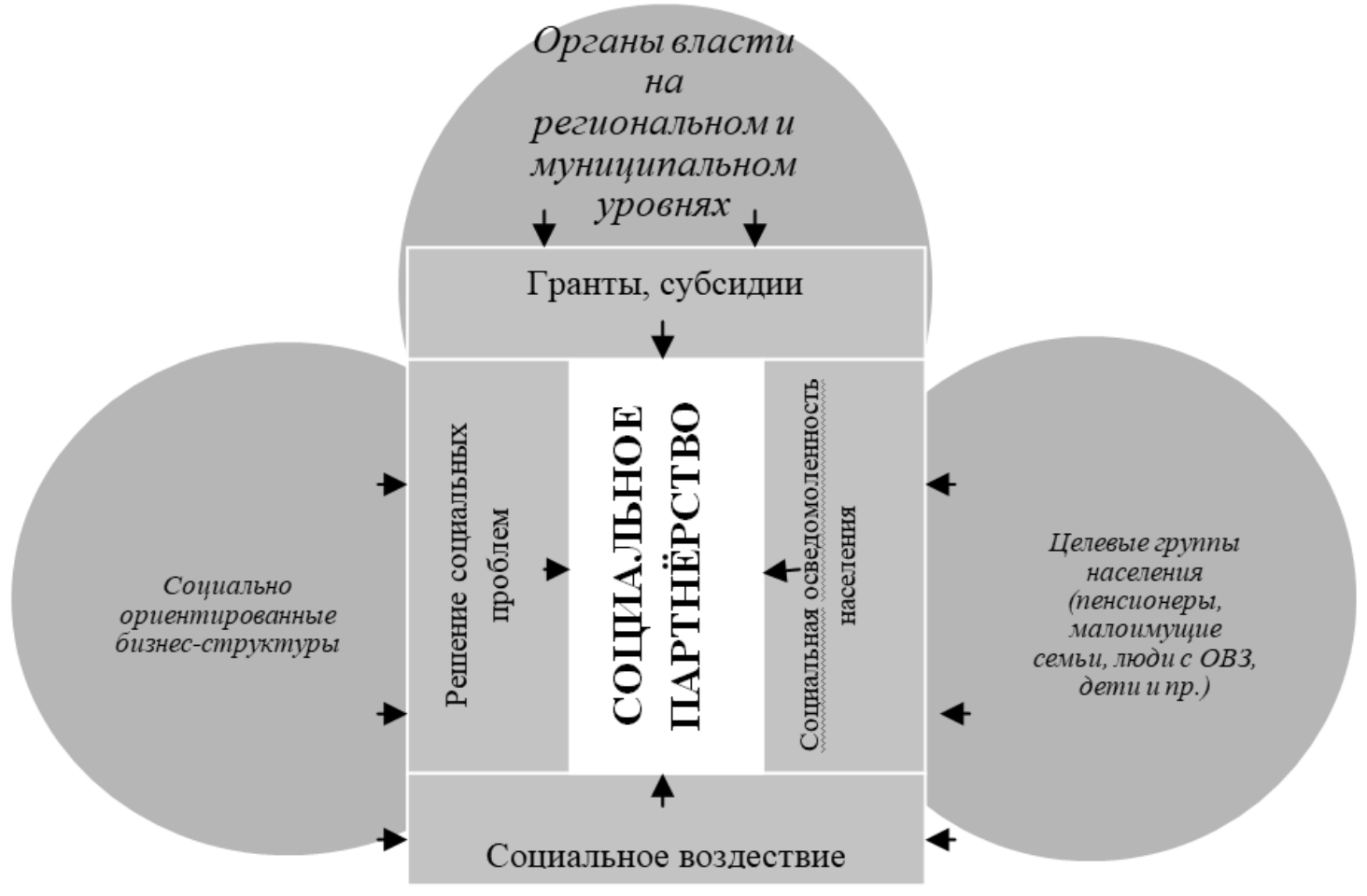

Рис. 3. - Системная модель регионального социального партнёрства * составлено Андросовой И.В. на основании $[3,8]$

циального партнёрства включает в себя органы региональной власти, социально ориентированные бизнес - структуры и целевые группы населения. Для эффективного функционирования социального партнёрства необходимо увеличение объемов государственной поддержки в виде грантов, субсидий, беспроцентных займов, льгот.

Взаимодействие с государством необходимо для выполнения организациями своей основной цели - решении социальных проблем. Участие целевых групп населения в социальном партнёрстве позволит повысить уровень информированности населения о социальном предпринимательстве как явлении. В результате комплексного взаимодействия и дополнения всех имеющихся ресурсов государства, бизнеса и общества формируется социальное партнёрство, положительный эффект которого будет проявляться в следующем:
- работа с социально незащищенными слоями общества, социализация уязвимых групп населения, реализация проектов, направленных на трудоустройство лиц без определенного места жительства и прочее;

- обеспечение трудовой занятости по средствам реализации социальных проектов, обеспечивающих самозанятость граждан;

- развитие культурной среды посредством максимального использования потенциала культурных учреждений.

Таким образом, социальное партнёрство является неотъемлемым элементом современного государства, направленным на решение социальных проблем с учетом удовлетворения потребностей органов власти, бизнеса и общества.

\section{ЛИТЕРАТУРА}

1. Аяганова М.П., Притворова Т.П., Мамраева Д.Г., Ташенова Л.В. Социальное предпринимательство: бизнес-модели и стратегии развития// Економічний часопис-XXI. 2019. Т. 178. № 7-8. С. 96-104.

2. Инструментарий анализа и прогнозирования структурных параметров региональной экономики: монография [Текст]/ под. ред. Ю.В. Вертаковой. Вертакова Ю.В., Плотников В.А., Положенцева Ю.С., Леонтьев Е.Д., Клевцова М.Г., Крыжановская О.А., Емельянов С.Г., Пролубников А.В., Хорьков А.В., Рушкова А.В. - Курск: ЮЗГУ, 2018. -359с.

3. Евченко А.В., Железняков С.С. Диагностика соответствия уровней экономического и социального развития районов Курской области// Известия Курского 
государственного технического университета. 2002. № 2 (9). С. 225-236.

4. Каталог предприятий, товаров и услуг социальных предпринимателей: [Электронный ресурс] // Режим доступа: https://soindex.ru/persons/index/ region_id:4198 (Дата обращения 17.10.2020)

5. Каширцева, А.Ю., Чарочкина Е.Ю. Социально-экономические факторы формирования эффективной экономики // Российская наука и образование сегодня: проблемы и перспективы. 2015. № 4 (7). С. 211-213.

6. Колодняя Г.В. Социальное предпринимательство: российская модель //Экономика и предпринимательство. 2019. № 9 (110). С. $672-675$.

7. Мальцева, И.Ф., Крыжановская 0.А. Институциональное обеспечение стратегического планирования в Российской Федерации / И.Ф.Мальцева, 0.А. Крыжановская // Известия Юго-Западного государственного университета. Серия: Экономика. Социология. Менеджмент. 2018. № 2 (27). С. 31 -38.

8. Орехова Е.А., Ромашкин Т.В. Социальное партнерство в российских реалиях: от теории к практике // Наука и общество. 2018. № 1 (30). С. $17-23$.

9. Симоненко Е.С., Кононов А.А. Сущность и возможный отраслевой состав многоотраслевых комплексов региона //Гуманитарные, социально-экономические и общественные науки. 2013. №7-2. С. 117-120.

10. Федеральный закон от 24.07.2007 № 209-Ф3 (ред. от 08.06.2020) «0 развитии малого и среднего предпринимательства в Российской Федерации»: [Электронный ресурс]//Режим доступа: http://www.consultant.ru/document (Дата обращения 17.10.2020)

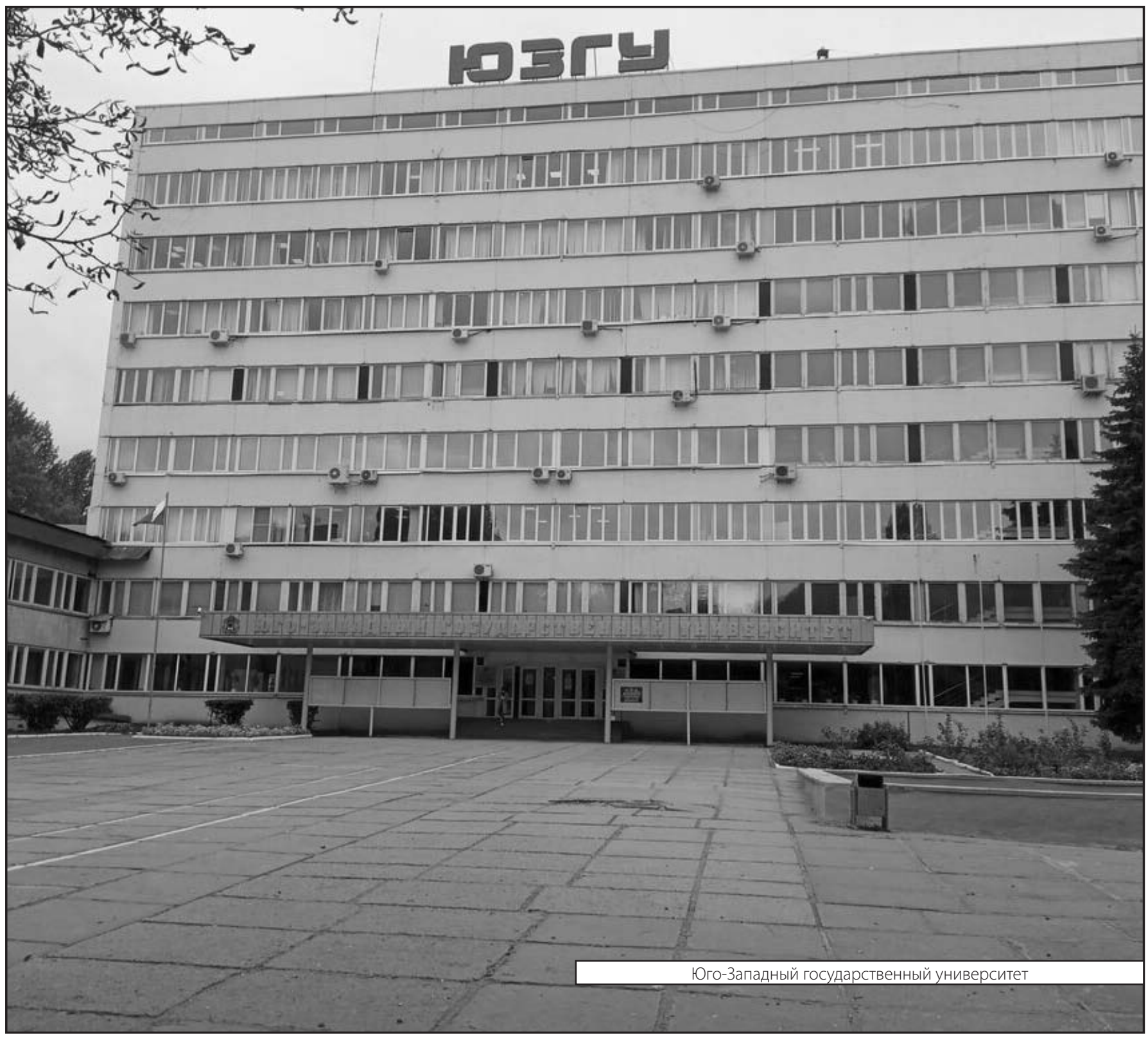

